\title{
Influence of socio-demographic variables on the choice of contraceptives among women attending ANC unit at specialist hospital Sokoto, Sokoto State, Nigeria
}

\author{
Aliyu Sokoto Sabo ${ }^{1 *}$, Lawali Yakubu ${ }^{2}$, Aliyu Alkammawa Luba ${ }^{1}$, Samira L. Ya` ${ }^{3}$, \\ A. T. Bakare ${ }^{4}$, Muhammad Fatima ${ }^{5}$, Isah M. Zayyanu ${ }^{6}$, Musa A. Zulkiflu²
}

${ }^{1}$ College of Nursing Sciences Sokoto, Sokoto State, Nigeria

${ }^{2}$ Department of Nursing Sciences, Faculty of Clinical Sciences, College of Health Sciences, Usmanu Dan Fodiyo University Sokoto, Nigeria

${ }^{3}$ Department of Nursing Sciences, College of Health Sciences, Federal University Birnin Kebbi, Nigeria

${ }^{4}$ Department of Psychiatry, Faculty of Clinical Sciences, College of Health Sciences, Usmanu Danfodiyo University

Sokoto, Nigeria

${ }^{5}$ College of Nursing and Midwifery, Sokoto, Nigeria

${ }^{6}$ Zamfara State Government House Clinic, Nigeria

Received: 15 May 2018

Accepted: 05 June 2018

\section{*Correspondence:}

Dr. Aliyu Sokoto Sabo,

E-mail: lawaliyakubu@yahoo.com

Copyright: (C) the author(s), publisher and licensee Medip Academy. This is an open-access article distributed under the terms of the Creative Commons Attribution Non-Commercial License, which permits unrestricted non-commercial use, distribution, and reproduction in any medium, provided the original work is properly cited.

\section{ABSTRACT}

Background: A contraceptive choice that couples make is a key component of the Sustainable Development Goal agenda and a major contributor to national health. In spite of the importance of increased contraceptive uptake among couples of reproductive ages, meeting the reproductive health rights of women remains an issue due to multi-faceted obstacles within complex environments. The issues which impact women's reproductive health rights in relation to contraception relate to availability, accessibility, affordability, literacy, tradition, and culture. This study explores the influence of socio-demographic data on the choice of contraceptives among women who are accessing family planning services at a Specialist hospital, Sokoto-Nigeria.

Methods: A cross sectional study was used in this quantitative research to generate data on contraceptive choices of women within the reproductive age (18-49 years) who are accessing family planning services at Specialist hospital, Sokoto. A structured questionnaire was used to elicit information from 352 respondents who were randomly sampled at a Specialist hospital, Sokoto-Nigeria. Data was analyzed using SPSS version 20.0. Descriptive statistics, correlation and regression analyses were used in the data analyses.

Results: The findings of this study established age, occupation and level of education to be related with the usage and choice of contraceptives among women attending family planning unit at a Specialist hospital in Sokoto.

Conclusions: The result of the study indicated that the socio-demographic data of the respondent, has a significant role in the choice of contraceptives among the women attending family planning unit of Specialist Hospital Sokoto.

Keywords: Birth Control, Choices, Contraceptives, Reproductive Health, Socio-demographic women 


\section{INTRODUCTION}

The contraceptive methods couples choose for birth control generates key issues in the reproductive rights and health of women.

The International Conference on Population and Development [ICPD] which took place in 1994 in Cairo, emphasized that reproductive health includes the right of men and women to have access to Family Planning FP encompasses the decision of women on the intended number of children to give birth to include the choice and decision not to have any children. ${ }^{1}$

The issue of couples deciding whether or not to have children is primarily influenced by external forces such as marital status, the cultural and socio-economic status of women. ${ }^{1,2}$ Cognitive and physical disabilities are also known to affect the woman's well-being and ultimately influences reproductive health decision making. ${ }^{1}$

Family planning (FP) is the capability of spouses, husband, partners or individuals to choose the number of children they desire, or they want and the time to have them. $^{3}$ This can be attained by the use of Family planning( FP) methods which is one of the most costeffective public health interventions center in decreasing a country's fertility rate. ${ }^{3}$ Family planning has also been found to assist gender equality as well as educational and economic empowerment for women. ${ }^{4}$ Despite the estimated 7.3 billion world population with projections up to 9.7 billion by 2050 and 11.2 billion by 2100 (United Nations / Department of Economic and Social Affairs, 2009).

Fertility decline methods aim at achieving demographic dividend with consequent decrease of poverty, improving socio- economic development and happiness of the couple and country at large. ${ }^{3}$ In Nigeria, it is projected that a reduction in fertility by one child per woman would lead to $13 \%$ increase in gross domestic product per capita within 20 years. $^{5}$ Nigeria is yet to get a very good dividend of FP as the choice and usage of contraception remains very low. ${ }^{6}$ Decreasing fertility rate of women to one child per woman will possibly cause an increase in the GDP to $13 \%$ in 20 years' time if properly implemented. ${ }^{7}$

In Nigeria, women who have a higher educational level are more likely to decide on the contraception to use than women with secondary or lower education. ${ }^{8}$ On the contrary, couples contraception choice is known to be higher if at least one partner has had a primary or higher education than if both had no education. ${ }^{9}$ However, women that poses higher education than their husbands tend to use and choose contraceptives they desire more than women who have less education compared to their husbands. ${ }^{10}$ Whilst only $15 \%$ of married couples were choosing and using the type of contraceptive they preferred, $10 \%$ did not use any type of modern contraception. ${ }^{11}$

The aim of this study is to explore the influence of sociodemographic data in the choice and utilization of contraceptives among reproductive women accessing family planning unit in specialist hospital Sokoto, Nigeria.

\section{METHODS}

A cross-sectional design was employed to find information from participants on the influence of sociodemographic data on the choices of contraceptives among women accessing Specialist Hospital in Sokoto. The relationship between the study variables was explored. Using a cross-sectional design, statistical and numerical analysis can be generalized among individuals or groups, or across a wider population to provide clarification on a prevailing event or phenomenon.

\section{Sample size and sampling technique}

Convenient sampling technique was employed to recruit study participants. The sample population was drawn from the FP clinic of Sokoto Specialist Hospital. This sampling technique is appropriate when the population consists of various types of people but identify with a specified event or phenomenon (contraceptive) over a stipulated period of time.

\section{Data collection}

A questionnaire was developed to elicit information from participants on contraceptive choices, uptake, and usage. The questionnaire was structured in sections with a focus on socio-demographic data of women accessing family planning unit of Specialist Hospital Sokoto.

Pre-testing: The designed questionnaire was pretested with 35 clients at the Maryam Abacha Women and Children's Hospital, Sokoto. The hospital had similarities with the type of population for the study. The findings of the pre-test were used to guide the researcher in making adjustments or amendments in the questionnaire for the original research. This pre-testing also helped the researcher to validate the questionnaire towards establishing the reliability of the instrument for the study.

Data collection procedure: Ethical clearance from the Chief Medical Director of Specialist Hospital for institutional approval where data were collected from women who volunteered to participate in the study Subsequently, clearance was given by the ethical committee of the specialist hospital Sokoto that allowed the researcher to conduct his research in the hospital. The aim of the research and its significance was discussed with potential respondents of the research using the study information on the questionnaire three nursing officers were trained as Research Assistants to assist in the 
administration of the questionnaires to women who met the inclusion criteria. Each questionnaire took approximately 45 minutes to 1 hour on complete. The need to respond to all questions in the questionnaire was emphasized. Data collection was completed within three weeks from the day institutional approval was given.

\section{Statistical analysis}

The analytic strategies used in the study was primarily informed by what best fits the data rather than the technique chosen beforehand. After the raw data was collected, the responses were coded and entered into SPSS 20.0 for analysis. Since the data collected was basically quantitative, it was analyzed descriptively which included frequencies and percentages. The results were presented using tables and figures. The statistical analysis used for the study was chi-square test of independence and binary logistic regression.

The Chi-Square test is used when to check the association between two categorical variables. If there is no association between variables, they are independent. Two variables are independent if the distribution of one in no way depends on the distribution of the other. If two variables are not associated (that is, if they are independent), then the knowing the value of the variable for some subject will not help to determine the value of the other variable for the same subject the multivariate statistical method examines the association of all the independent variables with the dependent variable and trims the inter-correlation among the independent variables if any. With independent variables measured on different scales, the most opposite multivariate tool is logistic regression.

A logistic regression was used in this study to investigate the association of all the independent variables individually discussed in relation to the dependent variable. These statistical tools were used because they were suitable means of breaking down and analyzing the generated data.

\section{RESULTS}

Table 1 shows the socio-demographic characteristics of the respondents. The results show 99 (28.1\%), 30-36 while $86(24.4 \%)$ were ages between 18-24. Education level of respondents revealed $133(37.8 \%)$ had tertiary education and $125(35.5 \%)$ had secondary education while 68 (19.3\%) had no formal education. Approximately, four-fifth $277(78.7 \%)$ majority of the respondents were Muslims while the remaining were Christians 75 (21.3\%). Out of the total respondents, 129 $(37.5 \%)$ were students, $121(35.2 \%)$ worked in the informal sector while $79(23.0 \%)$ were in the formal sector employment. Some respondents $(n=121,36.9 \%)$ noted their husbands were having other wives (polygamous) while more than half $(n=207,63.1 \%)$ said otherwise. More than half of the respondents $(n=191$,
$56 \%$ ) had between 1-3 children while $33(9.7 \%)$ of the respondents had no children.

With regards to the dependent variable, respondents indicated that they are currently using contraceptives in the reference category whilst those who indicated otherwise is the case variable. The reference categories of the various response variables have clearly indicated a negative coefficient (or odds ratio - OR less than 1) and that the particular relation is reversed. The corresponding significance probability ( $\mathrm{p}$-value) shows whether the association is significant or not. The odds of women from Islamic religion using contraceptives was 157.73 times the odds of Christian respondents $[\mathrm{OR}=157.73$ (95\% CI, $10.939,2274.475)]$. In the analysis, this association was found to be statistically significant.

\section{Table 1: Showing socio-demographic data report of respondents.}

\begin{tabular}{|c|c|c|c|}
\hline Category & Level & Frequency & Percent \\
\hline \multirow{4}{*}{ Age (years) } & $18-24$ & 86 & 24.4 \\
\hline & $25-29$ & 72 & 20.5 \\
\hline & $30-36$ & 99 & 28.1 \\
\hline & $37-49$ & 95 & 27 \\
\hline \multirow{4}{*}{ Education } & None & 68 & 19.3 \\
\hline & Basic & 26 & 7.4 \\
\hline & SHS & 125 & 35.5 \\
\hline & Tertiary & 133 & 37.8 \\
\hline \multirow{2}{*}{ Religion } & Islam & 277 & 78.7 \\
\hline & Christianity & 75 & 21.3 \\
\hline \multirow{4}{*}{ Occupation } & Student & 129 & 37.5 \\
\hline & Unemployed & 15 & 4.4 \\
\hline & Formal & 79 & 23 \\
\hline & Informal & 121 & 35.2 \\
\hline \multirow{3}{*}{ Polygyny } & No & 207 & 63.1 \\
\hline & Yes & 121 & 36.9 \\
\hline & None & 33 & 9.7 \\
\hline \multirow{3}{*}{$\begin{array}{l}\text { Number } \\
\text { dependents }\end{array}$} & $1-3$ & 191 & 56 \\
\hline & $4-6$ & 87 & 25.5 \\
\hline & $>6$ & 30 & 8.8 \\
\hline
\end{tabular}

The odds of women with rivals who do not use contraceptive was 0.3 times less likely the odds of those with rivals $[\mathrm{OR}=0.307(95 \% \mathrm{CI}, 0.122,0.770)]$. On age, the odds of women aged between 18-24, 25-29 and 30-36 years using contraceptives were 591, 1.200, 2.599 times the odds of women aged between 37- 48 [OR= $0.591(95 \% \mathrm{CI}, 0.141,2.471)]$ and $[\mathrm{OR}=1.200(95 \% \mathrm{CI}$, $0.345,4.174)] \quad[\mathrm{OR}=2.599(95 \% \mathrm{CI}, 0.843,8.011)]$ respectively. This analysis was however not statistically significant. Furthermore, the odds of women having between 1-3 and 4-6 children using contraceptives was reduced 0.04 and 0.012 times less likely as compared to women with more than six children $[\mathrm{OR}=0.04$, $(95 \% \mathrm{CI}$, $0.005,0.362)], \quad[\mathrm{OR}=0.012,(95 \% \mathrm{CI}, 0.001,0.106)]$ respectively. The test analysis proved to be statistically significant. However, the odds of women with no children using contraceptives was 0.248 times less likely 
as compared to women with more than 6 children $[\mathrm{OR}=0.248,(95 \% \mathrm{CI}, 0.021,2.873)]$. In the analysis, this was statistically and significantly associated.

Moreover, there was no statistically significant association between education level and contraceptive usage. With the exception of women with no formal education, the odds of women with Basic and Secondary/Technical education using contraceptives were all less likely as against those with Tertiary education $[\mathrm{OR}=1.119,(95 \% \mathrm{CI}, 0.200,6.267)],[\mathrm{OR}=0.980,(95 \%$ CI, 0.142, 6.778)] and $[\mathrm{OR}=0.854,(95 \% \mathrm{CI}, 0.244$, 2.986)] respectively.
Finally, respondents' occupation was found to be statistically significantly associated with contraceptive usage in women. The odds of women being a student, unemployed and formally (public and private sector employed) using contraceptives were all less likely as compared to those who are informally employed and without education $[\mathrm{OR}=0.038,(95 \% \mathrm{CI}, 0.008,0.172)]$, $[\mathrm{OR}=0.160,(95 \% \mathrm{CI}, 0.030,0.864)]$ and $[\mathrm{OR}=0.012$, (95\% CI, 0.001, 0.108)] respectively (Table 2).

Table 2: Associations between socio-demographics characteristics and contraceptive usage amongst reproductive women.

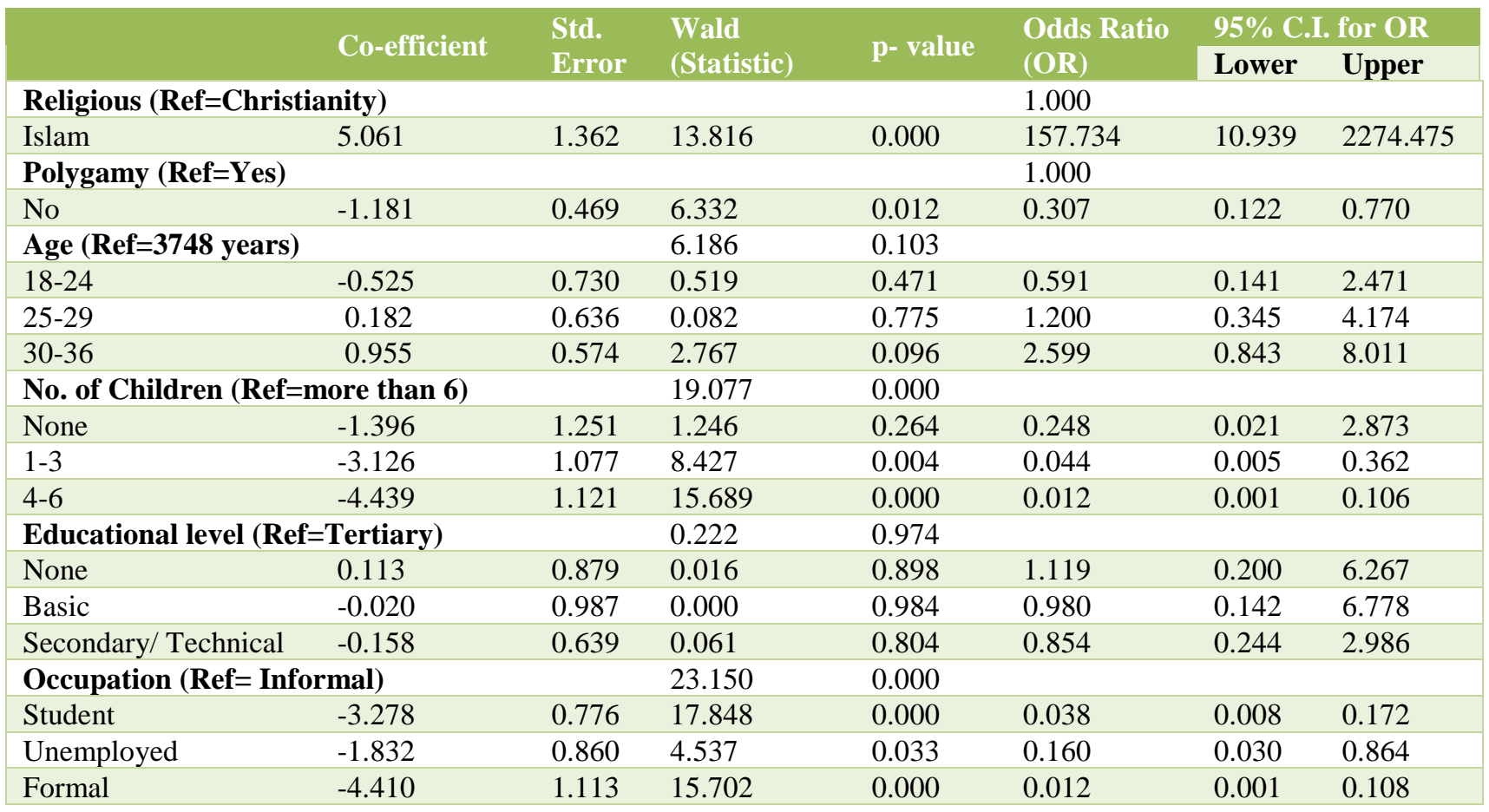

\section{DISCUSSION}

From the study findings, it is seen that those with post/ higher/ tertiary education, have the highest of the respondents in the study which indicates that the level of educational qualification has a significant role to play in contraceptive usage. From the findings, it is obvious that women with higher educational qualification have the highest percentage of the respondents 133 (37.8\%), followed by those with secondary education 125 (35.5) while women with the primary educational background, have the lowest percentage of respondents $26(7.4 \%)$. The finding of this research established that women with higher education are more likely to use contraceptives than their counterparts in secondary school and those in secondary are likely to use contraceptives than those with primary education. This finding is similar to the that of
Rahman and Kabir which indicated that the level of education of respondents has a significant role in the usage and choice of contraceptives. ${ }^{12}$ The finding of this study is also similar to the study finding of Dynes, Stephenson, Rubardt, and Bartel which emphasize that women with higher level of education have a better chance of using and choosing modern contraceptives than their counterparts in the lower educational cadre. ${ }^{13}$

It is worthy of note that, the findings this study again establish age and level of education are directly related with the usage and choice of contraceptives among women accessing family planning unit at a Specialist hospital in Sokoto. The outcomes of this study which relate to occupation of respondents indicate that students have the highest percentage of contraceptive usage, representing 129 (36.6\%) out of 352 while those who are 
formally employed are less likely to use contraceptives. This in juxtaposition with a Tanzanian study confirms that the type of occupation plays a major role in choice and usage of contraceptives. ${ }^{14}$

\section{CONCLUSION}

The result of the study indicated that the sociodemographic data of the respondent, has a significant role in the choice of contraceptives among the women accessing family planning unit of Specialist Hospital Sokoto.

\section{Recommendations}

The finding of this study has revealed the influence of socio-demographic data of the respondent on the use and choice FP methods in the Specialist Hospital in Sokoto has a significant role in the choice of FP therefore, there is need for policy makers and stake holders to partner with the management of specialist hospital in achieving sustainable benefits on contraceptive use and choice among the client accessing specialist hospital Sokoto and the state at large. The stakeholders should liason with the FP unit for necessary assistance in terms of enough provision and supply of FP drugs and creation of a conducive atmosphere/ environment for the service providers and clients.

It was also recommended that the Sokoto State and Nigeria at large should enlighten the populace on the importance of family planning methods using social media platforms as it is the common means of communication in this contemporary world.

\section{ACKNOWLEDGMENTS}

Authors would like to thank Professor Ernestina Safoa Donkor, Dr. Mary Ani-Amponsah, Dr. Gladys Dzansi for their support during study.

Funding: No funding sources Conflict of interest: None declared

Ethical approval: The study was approved by the Noguchi Memorial Institute for Medical Research

\section{REFERENCES}

1. Tobergte, Curtis. Program of Action-Adopted at the International Conference on Population and Development, Cairo. J Chemical Info Modeling. 2013;53. Available at: https://doi.org/10.1017/CBO9781107415324.004

2. Mosha I, Ruben R, Kakoko D. Family planning decisions, perceptions and gender dynamics among couples in Mwanza, Tanzania: a qualitative study.
BMC Public Health. 2013;13(1):523. Available at: https://doi.org/10.1186/1471-2458-13-523

3. Graff M, Bremner J. A practical guide to population and development. Population Reference Bureau. Disponível em: http://www. prg. org (consultado a 8 de Agosto de 2014). 2014 Jun.

4. Yue K, O'Donnell C, Sparks PL. The effect of spousal communication on contraceptive use in Central Terai, Nepal. Patient Edu Counseling. 2010 Dec 1;81(3):402-8.

5. Canning D, Karra M, Wilde J. A macrosimulation model of the effect of fertility on economic growth: Evidence from Nigeria. Papier de travail, Harvard University, Cambridge, MA. 2013.

6. National Population Commission (NPC) [Nigeria] and ICF International, Nigeria Demographic and Health Survey 2013 National Population Commission Federal Republic of Nigeria, 2013. 538.

7. Iheyinwa CS, Oladosu M. Socio-Demographic factors, contraceptive use and fertility preference among married women in south-south region of Nigeria. 2016;504-10.

8. Asekun-Olarinmoye EO, Adebimpe WO, Bamidele JO, Odu OO, Asekun-Olarinmoye IO, Ojofeitimi EO. Barriers to use of modern contraceptives among women in an inner-city area of Osogbo metropolis, Osun state, Nigeria. Int $\mathbf{J}$ Women's Health. 2013;5:647.

9. Ibisomi. Is age difference between partners associated with contraceptive use among married couples in Nigeria? International Perspectives on Sexual and Reproductive Health. 2014. Available at: https://doi.org/10.1363/4003914

10. Stephen AA, Enoch PM. Modern contraceptive use, sex refusal, spousal difference in level of education among married women in Nigeria: Are they interrelated?. Int J Humanities. 2014;4(6):217-30.

11. Rahman MM, Kabir M. Knowledge of adolescents on contraception and dynamics of its use. Health and Population: Perspectives and Issues. 2005;28(4):16477.

12. Dynes M, Stephenson R, Rubardt M, Bartel D. The influence of perceptions of community norms on current contraceptive use among men and women in Ethiopia and Kenya. Health Place. 2012 Jul 1;18(4):766-73.

13. Michael. Stable Marital Relations Attending Health Stable Marital Relations Attending Health. 2012.

Cite this article as: Sabo AS, Yakubu L, Luba AA, Ya`u SL, Bakare AT, Fatima M et al. Influence of socio-demographic variables on the choice of contraceptives among women attending ANC unit at specialist hospital Sokoto, Sokoto State, Nigeria. Int J Reprod Contracept Obstet Gynecol 2018;7:2565-72. 


\section{ANNEXURE}

\section{Contraceptive use questionnaire}

\section{Title}

Quality service of and client satisfaction with focused antenatal care services in health facilities in Bauchi State, Nigeria

\section{Instructions}

Respondents are requested to tick the suitable option and write in the boxes where a number is required

\begin{tabular}{|c|c|c|c|}
\hline \multicolumn{4}{|c|}{$\begin{array}{l}\text { Section one: respondent background } \\
\text { Contraceptive use questionnaire }\end{array}$} \\
\hline \multirow{3}{*}{$\begin{array}{l}1 \\
2\end{array}$} & \multicolumn{3}{|l|}{ Your Name } \\
\hline & \multicolumn{3}{|l|}{ How old are u? } \\
\hline & Questions & Choices & Choices \\
\hline \multirow{3}{*}{3} & \multirow{3}{*}{ What is your level of education? } & None & Secondary \\
\hline & & Primary & Post Sec/ \\
\hline & & JSS & Higher \\
\hline \multirow{5}{*}{4} & \multirow{5}{*}{ What do you do for a living? } & Student & Trader \\
\hline & & Farmer & Home keeper \\
\hline & & Unemployed & Public servant \\
\hline & & Other informal & Employment \\
\hline & & employment & Other Formal \\
\hline \multirow{2}{*}{5} & \multirow{2}{*}{ What is your religious affiliation? } & Islam & Traditional \\
\hline & & Christianity & Other \\
\hline \multirow{4}{*}{6} & \multirow{4}{*}{ What is your marital status? } & Single & Co-habiting \\
\hline & & Divorced & Widowed \\
\hline & & Married & \\
\hline & & Separated & \\
\hline 7 & If married, does your husband have another wife? & Yes & No \\
\hline 8 & How many living children do you currently have? & & \\
\hline
\end{tabular}




\section{Section two: contraceptive knowledge and utilization}

\section{Questions}

9

Do you know ways/ methods to delay or avoid pregnancy

(contraceptives)?

If yes answer to the following

10

\section{Responses}

Yes

$\begin{array}{ll}\text { Methods } & \text { Responses } \\ & \text { Yes No }\end{array}$

Female

sterilization

Male sterilization

Implants

IUD

Injectables

Pill

Female condom

Male condom

Diaphragm

Form or jelly

Calendar method

Withdrawal

Lactation

amenorrhea

method

Emergency

contraception

Other (specify)

11 Have you or your partner ever used any of these methods to delay or avoid pregnancy?

12 How many living children did you have at that time you first used contraception, if any

13 If ever used any method, have you in the past 12 months used any of these methods?

Yes

No

14 If currently using, which method are you currently using to delay or avoid pregnancy?

IUD

Injectables

Pill

Female condom

Male condom

Diaphragm

Form or jelly

Calendar method

Withdrawal

Lactation Amenorrhea Method

Emergency contraception

Other (specify)

Where did you mainly obtain the method?

Public hospital/clinic

Private hospital/clinic

Pharmacy/drug store

Other (specify)

What informed your choice of that method?

Affordability

Privacy

Easy access available

Long term protection

Short term protection

Side effects of other methods

Convenience

Why are you not using any method to delay or avoid pregnancy? 
Religious beliefs

Traditional beliefs

Partner refuses

Expensive

Side effect

Abstenance/partner travelled

Amenorrheoic

Do not wish to avoid pregnancy

Currently pregnant

Other (specify)

$15 \quad$ Where did you mainly obtain the method?

Public hospital/clinic

Private hospital/clinic

Pharmacy/drug store

Other (specify)

What informed your choice of that method?

Affordability

Privacy

Easy access available

Long term protection

Short term protection

Side effects of other methods

Convenience

16 Why are you not using any method to delay or avoid pregnancy?

Religious beliefs

Traditional beliefs

Partner refuses

Expensive

Side effect

Abstenance/partner travelled

Amenorrheoic

Do not wish to avoid pregnancy

Currently pregnant

Other (specify)

17 Would you consider using family planning in future to delay or prevent pregnancy?

Yes

No

18 Which of the methods would you consider using in future to delay or prevent pregnancy? 